\title{
Para um novo humanismo: contribuições da Psicologia Social
}

\author{
EDA TEREZINHA DE OLIVEIRA TASSARA \\ e SUELI DAMERGIAN
}

A antecipação do futuro e o neoliberalismo

"Nós, que sobrevivemos aos Campos, não somos verdadeiras testemunhas.
Esta é uma idéia incômoda que passei aos poucos a aceitar, ao ler o que
outros sobreviventes escreveram - inclusive eu mesmo, quando releio meus
textos após alguns anos. Nós, sobreviventes, somos uma minoria não só
minúscula, como também anômala. Somos aqueles que, por prevaricação,
habilidade ou sorte, jamais tocaram o fundo. Os que tocaram, e que viram a
face das Górgonas, não voltaram, ou voltaram sem palavras.”

Primo Levi apud Eric Hobsbawn (1994:11)

$\mathrm{T}$

ENDO NASCIDO logo após a Segunda Grande Guerra como uma reação teórica e política ao Estado intervencionista e de bem-estar, ao longo dos anos 80 a ideologia do neoliberalismo triunfou na Europa e na América do Norte, e continua avançando sem cessar, atingindo, com sua influência, regiões do planeta até então intocadas. Trata-se, no dizer de Anderson (1995:Q2), de um movimento ideológico em escala verdadeiramente mundial que, a partir da proposta do grupo de Mont Pelerin em 1947, vem se afirmando como "um corpo de doutrina coerente, autoconsciente, militante, lucidamente decidido a transformar todo o mundo à sua imagem, em sua ambição estrutural e sua extensão internacional".

Se a disseminação do paradigma neoliberal é inegável, por outro lado, a análise causal desse processo de expansão não é uma tarefa trivial. Como compreender o êxito político e ideológico do neoliberalismo, malgrado a não consecução de seus objetivos econômicos e sociais através da implementação de suas preconizações? Apesar de não ter produzido uma revitalização do capitalismo avançado e de ter contribuído para a drástica criação de sociedades humanas cada vez mais desiguais, a hegemonia do neoliberalismo produz-se, sustenta-se e propaga-se hodiernamente em um panorama impressivo com relação ao qual parece não haver outra alternativa senão a de submissão às suas normas. Uma nova forma de despotismo gerada pelas ausências que permanecem no horizonte do mundo contemporâneo.

A leitura desse panorama histórico permite interpretá-lo como uma pro- 
dução estratégica que se estruturou mediante a justaposição, por simultaneidade, do colapso do comunismo na Europa Oriental e da entrada do Mundo Ocidental na etapa histórica da Terceira Revolução Industrial, com o triunfo de um tipo específico de capitalismo, aquele liderado e simbolizado por Reagan e Thatcher nos anos 80. Tudo se passa como se tivesse havido uma antecipação determinista da história, a vitória profética de específicas doutrinas, as quais se conotam com a vitória do Ocidente, a vitória do capitalismo frente ao socialismo e, finalmente, a vitória do tardo-capitalismo vigente, ou seja, do capitalismo de impostação neoliberal.

Velando-se, pela ocultação do domínio estabelecido entre o processo de criação simbólico-científico-tecnológico pelo processo produtivo, as verdadeiras relações entre o sistema de produção e a sociedade, velam-se também as verdadeiras determinações da profunda transformação levada a efeito na sociedade contemporânea, substrato das novas relações étnicas, sociais, culturais, econômicas e políticas que se corporificam no denominado sistema-mundo.

A análise da hegemonia do liberalismo radical implica, portanto, também a análise da luta que se desenvolve pela propriedade do conhecimento e pelo domínio do processo de criação simbólico-científico-tecnológico (Tassara, 1994). Aponta para a identificação de uma ação de propaganda (Moscovici, 1961), visando à construção de uma representação social da ciência vista como naturalmente idêntica à configuração de seu domínio pela Nova Aliança - aliança que se processou gradativamente entre cientistas, industriais, militares e políticos (19451960) e que se consolidou na hegemonia dos Estados Unidos na pesquisa mundial (Pestre, 1992) - e, desta, como expressão natural da vitória da ideologia neoliberal. Tal visão mostra-se como elaboração instrumental de uma modalidade de expressão de um grupo de interesses em situação de conflito e visa ao domínio do processo mundial de construção do futuro. O conflito está situado nas diferentes opções estratégicas de interface entre ciência, tecnologia, produção e sociedade, cada uma das quais comprometidas com sistemas arbitrários de valores de verdade. Estas opções estão sendo apresentadas como se fossem determinações naturais, portanto, idênticas aos paradigmas neoliberais projetados, tendo em vista associá-los a imagens difusas representando indiscernibilidade entre o domínio do processo de produção, a Nova Aliança e o neoliberalismo, e, as propriedades dessa produção. A ação de propaganda vem atuando através da organização de temas e princípios visando a reduzir o impacto da ação de difusão (Moscovici, 1961) de processos autônomos colocados em movimento por forças sociais anti-sistemáticas, uma vez que, pelas suas características de descontinuidade e não-ordenação, não poderiam ser por ela controlados. Ou seja, esta luta estratégica visa, por meio da propaganda, a ocultar o fato da propriedade por seqüestro do conhecimento científico e tecnológico por forças sistemáticas, sustentando a conclusão de que esta seria a direção natural histórica do processo de produção. Essa passagem é feita mediante a tática de impedimento ou dificultação da emergência da consciência de tal domínio e objetiva a conquista do poder de determinação do futuro. Como resistir? Como contrapor-se estruturando pro- 
postas alternativas que possam vir a catalisar forças anti-sistemáticas na direção de outros paradigmas?

O âmbito e a complexidade desta análise dinâmica inscreve-a necessariamente em campo interdisciplinar, para o qual a psicologia social pode trazer elucidativas contribuições. Tais contribuições tornam-se mais relevantes quando se considera como seu domínio a compreensão das inter-relações dos aspectos cognitivos e afetivos de representações sociais compartilhadas por grupos, examinando quais condições sociais, linguagens e instrumentos de comunicação estão envolvidos na formação e preservação de um sistema de representações, e descrevendo as condições sob as quais esta estrutura ajuda a criação de uma visão coletiva (Jodelet apud Hughes, 1993). Como se produz a impressão de morte da história, com suas conseqüências motivacionais sobre o campo de ação de forças anti-sistemáticas, mediante a criação da idéia de antecipação de vitória de determinadas doutrinas e programas políticos?

Deve-se considerar que antecipar, em suas diferentes acepções, significa uma ação que ocorre antes de um tempo marcado, determinado, previsto. Antecipar uma visão-invenção significa, então, criar algo em algum tempo passado de uma referência temporal presente na qual esta mesma visão-invenção se impõe socialmente como uma nova solução convencionada para um problema genérico, quer de ordem prática, quer especulativa (Tassara, 1995).

Assim, uma solução antecipada apresenta-se post hoc como uma alternativa vitoriosa afirmando-se pretensamente como a melhor no panorama virtual das possibilidades racionais. Como distinguir uma vitória política de uma vitória racional?

Em decorrência, perscrutar o futuro, antevendo caminhos a serem trilhados pelos processos históricos, significa construir argumentos que explicam, em um tempo passado, ocorrências de um tempo presente, futuro daquele passado, prevendo a vitória de determinadas idéias em detrimento de outras. Como distinguir uma vitória de argumentos de uma vitória de estratégias de imposição de argumentos?

Além disso, a modernidade histórica tem como característica o novo, nela, constituir um valor positivo que se impõe como bom e desejável em si. Por outro lado, aceitar o novo como um bem significa aceitar a ocorrência da mudança como natural, com a conseqüente alienação do caráter eletivo desse valor. Assim, na sociedade histórica tardo-capitalista, ao termo mudança associam-se conotações de progresso sustentando a conclusão de que "vivemos em um mundo de progresso em todos os níveis de nossa existência" (Wallerstein, 1994:138). Nestes termos, mudança, novo e progresso têm significações similares, confundindo-se entre si em nível de competência semântica.

Como, nesse panorama ideológico, delimitar quando um novo símbolo visão, prática, argumento ou invento - transformou-se em um antigo, devendo ser substituído por um novo novo? Como uma dada criação individual - e/ou - 
grupal torna-se um instrumento convencionado aceito coletivamente? Quem tem o poder de determinar a vitória técnica ou política de uma dada solução? Quanto desta solução significa uma antecipação porque se tornou vitoriosa? Como distinguir o novo que substitui o antigo por tê-lo tornado obsoleto, da obsolescência planificada que impõe legitimidade a um dado e particular novo?

Em outra vertente de considerações, pode-se apontar o conflito existente entre a teoria voluntarista da ação e a determinação da ação por coisas não voluntárias - a não simetria entre a intencionalidade e a ação - como um dos problemas fundamentais da psicologia contemporânea. Sob tal configuração, a psicologia social é inscrita no debate filosófico contemporâneo, apresentando-se como elemento heurístico na geração de idéias para uma crítica de relações entre "ética, política e simbolismo" (Marramao, 1990:10s). Suas contribuições adviriam da crítica do sujeito histórico, aplicada na análise das questões de identidade e dos níveis de relação entre o consciente e o inconsciente, da ação de fatores de preterintencionalidade sobre o agir humano.

Emerge assim, então, a abordagem filosófica da crítica do progresso, visto como um produto típico do racionalismo ocidental e "um caso típico de heterogênese dos fins das metas". Como projetos baseados em preferências e valores dos indivíduos e dos grupos sociais acabam por produzir efeitos negativos no plano coletivo? Como se criou este "fosso entre o mundo onde se realizam os produtos humanos e os projetos da existência humana?" (Marramao, 1990:11s).

Ainda a esse respeito, não há quem consiga dominar os resultados do progresso técnico. Introduz-se, dessa forma, outra temática: a dos limites sociais para o desenvolvimento, decorrentes das resistências culturais, ideológicas e psicológicas, estruturando-se sobre aspectos inconscientes da interação humana (Damergian, 1988) e gerando um campo de desilusões frente a expectativas criadas que exigem decodificação. Assim, tal temática imbrica-se com o mundo do simbólico cuja apreensão crítica é essencial para a clarificação da questão dos atores da ação social. Como se produz a falsa consciência do real?

No presente artigo tem-se por objetivo delimitar um campo argumentativo no qual se inscrevem tais perplexidades, visando a contribuir para a compreensão de como, à luz de cenários vistos pela psicologia social, se instauram, se propagam e se mantêm determinadas formas de relações humanas nas sociedades mundializadas tardo-capitalistas. Como conciliar a constatação racional de que a história se faz no próprio processo histórico com as frustrações de expectativas relativas a projetos baseados em preferências e valores de indivíduos e grupos sociais, que reduzem suas participações e os esvaziam de poder frente a esse mesmo processo?

\section{Uma leitura panorâmica da nova ordem mundial}

“É bom lembrar: o que chamamos hoje de globalização era chamado, há cerca 
de um século atrás, de imperialismo. Este conduziu a rupturas sociais e políticas que disseminaram regimes despóticos e, mais cedo ou mais tarde, paralisaram as economias submetidas ao poder totalitário.

Será que desejamos ver o próximo século nascer sob a égide de conflitos cuja natureza nos legaria uma nova geração de regimes autoritários?”

Alain Touraine (1996:5-7)

Designa-se como Nova Ordem Mundial à nova realidade emergente das relações políticas e econômicas internacionais contemporâneas. Nela, as humanidades da Terra percebem-se vivendo em um sistema mundial de produção de mercadorias, articulado e em movimento, do qual as economias desenvolvidas, subdesenvolvidas, socialistas e capitalistas fazem parte. Não há mais economias nacionais autônomas funcionando de maneira autônoma. Criou-se uma grande economia que está por cima da compreensão de nacionalidades. Além disso, essa Nova Ordem Mundial vem significando também uma explosão da miséria, da desordem, da exclusão e da fragmentação em determinados pontos do mundo. Verifica-se que tal dualidade - articulação mundial da economia, integração crescente da informação, de um lado, e centralização burocrática e do poder, empobrecimento das nações do sul do planeta, quebra das economias socialistas, intensificação dos conflitos políticos, econômicos e raciais intestinos ao Primeiro Mundo, de outro - não consegue mais ser explicada exclusivamente por oposições simples do tipo capitalismo-socialismo, democracia-autoritarismo, ou outras categorias bipolares.

Por outro lado, conforme analisa Attiná (1989), no mundo contemporâneo, do ponto de vista político, verificaram-se e estão em curso mudanças que atropelam os sistemas dos Estados porque atropelam características fundamentais da vida dos homens sobre o planeta; mudanças de natureza variada que, em seu conjunto, têm efeitos convulsivos sobre os modos de ocupação e desfrutamento do mundo. Às atividades e às relações dos dois sistemas fundamentais da política - os Estados e o sistema internacional - acrescentam-se, hoje, as atividades e as relações em níveis transnacional e intermediário, aos quais pertencem as atividades e as relações levadas a efeito por indivíduos e sobretudo por empresas econômicas, associações, organizações e redes sediadas em dois ou mais Estados, mas que não dependem dos governos dos Estados. Tais atividades e relações interferem - deliberadamente ou não - com as políticas internas dos Estados, que são feitas por instituições e atores políticos internos, e com a política do sistema internacional, elaborada pelos governos e pelas instituições intergovernamentais como as organizações internacionais e os regimes econômicos mundiais. A ligação entre os sistemas internos e o sistema internacional operada pelos atores do nível transnacional é o fator principal da emergência de um sistema global que pode ser concebido como o conjunto dos três níveis de política: estatal, internacional e transnacional.

Por outro lado, a análise da mudança da organização sistêmica internacional deve considerar dois fatores imbricados: as grandes competições entre agre- 
gados de Estados que refletem as principais fraturas sociais do sistema e os grandes problemas com soluções controversas.

$\mathrm{Na}$ análise do sistema internacional devem ser consideradas relevantes, para interpretar a evolução de sua organização, três fraturas (Attiná, 1993):

- a primeira, deriva da divisão internacional do trabalho da economia capitalista que produz a estratificação econômica dos Estados: pode-se utilizar a denominação convencional de fratura norte-sul, referindo-se não somente aos problemas de subdesenvolvimento mas, em geral, aos conflitos sobre mecanismos, estruturas e processos da economia mundial que têm lugar entre agregados de Estados com diferentes níveis de desenvolvimento econômico e diferentes estruturas econômicas;

- a segunda fratura concerne à competição sobre a autonomia interna e internacional dos Estados derivados da resolução do colonialismo europeu e da formação de um único sistema político internacional em conseqüência da expansão do sistema dos Estados europeus e da civilização européia no resto do mundo: pode-se utilizar a denominação de fratura centro-periferia;

- a terceira, influenciou fortemente a evolução da organização do sistema internacional contemporâneo sobretudo na primeira década depois de sua formação: trata-se da fratura leste-oeste entre os Estados que escolheram o capitalismo ou o socialismo como modelos de seus respectivos regimes econômicos, sociais e políticos internos.

Dessa forma, é em função de afinidades dos Estados em campos que estão em direta relação com as principais fraturas do sistema, isto é, no campo dos recursos materiais e econômicos (norte-sul), no campo da constituição políticocultural (centro-periferia) e no campo do regime interno (leste-oeste) que se configuram as políticas externas dos Estados contemporâneos.

Ainda segundo Attiná (1993), outro elemento de complexidade do sistema político internacional, assumido em concomitância com os processos de globalização, reside no crescente número de grandes problemas que são comuns a todos os Estados. Tais problemas dizem respeito ao uso dos bens, recursos e valores raros do sistema global; sobre os mesmos abrem-se fortes controvérsias entre os governos porque se trata de problemas aos quais podem ser dadas diversas soluções alternativas. São eles, entre outros, problemas de reequilíbrio dos desníveis de desenvolvimento econômico entre os Estados e as áreas do mundo, problemas da defesa dos direitos humanos e da democracia, problemas da autodeterminação dos povos e da proteção dos grupos étnicos minoritários, problemas dos fluxos migratórios por motivos econômicos, problemas da recolocação de grandes massas de exilados por motivos políticos, problemas da regulamentação e regimentação do aproveitamento dos recursos naturais comuns (espaço, atmosfera, oceanos etc.) e dos recursos materiais e humanos raros, entre os quais se inclui o conhecimento nos campos científico e tecnológico. 
Em conseqüência dos efeitos de interdependência e interconexão que os processos de globalização têm sobre as decisões e sobre as políticas internas da maior parte dos Estados contemporâneos, de fato, os governos não podem exercer as suas funções senão apelando para formas de cooperação e coordenação internacionais. As conquistas tecnológicas aplicadas às indústrias e aos serviços, e a maturação de aspirações sociais, culturais e políticas que não podem estar contidas dentro dos confins estatais nem ser subordinadas à vontade dos governos criam, portanto, problemas internacionais que não se resolvem senão por intervenção governamental a qual, para ser eficaz, deve ser coordenada por - ou mesmo dar lugar a - regulamentações e regimes internacionais (Attiná, 1993).

Assim, nesse contexto geopolítico, inscreve-se contemporaneamente o termo desenvolvimento, um dos itens da agenda internacional significando várias coisas, a cada uma das quais corresponderão processos virtuais diferenciados de regulamentação e regimentação do uso dos recursos naturais e humanos raros (Seabra et al., 1994).

Tal virtualidade delimita um campo de forças sociais em conflito tendo em vista interesses de aproveitamento do patrimônio material e não-material comum às humanidades da Terra. As forças em conflito visam a exercer influências imediatas sobre a construção da sociedade, plasmada segundo seus interesses determinados, particulares e setoriais, portanto, seus interesses não-generalizáveis e nem tematizáveis na esfera pública. Velados os verdadeiros conflitos, corporificam-se os mesmos na colocação em movimento de forças de informação, contra-informação e desinformação estratégicas, as quais, com maior ou menor grau de sistematização, objetivam influenciar as formas de representação da realidade histórica compartilhadas pelos diferentes grupos sociais, na luta pela imposição de uma alternativa como solução. Assim, a esfera da opinião pública, alargada de fato contemporaneamente pela difusão da informação nas mídias eletrônicas e por suas conseqüências sobre as relações humanas, políticas e sociais, esvazia-se de poder: de um lado mantém latente a natureza particular dos interesses em conflito que se concretizam em imposições de caminhos alternativos; de outro, produzindo a propagação velada de interesses, reduz a participação dos cidadãos à aclamação de escolhas políticas pré-confeccionadas.

Ainda a esse respeito, observa-se que os interesses constituídos na - e pela Nova Ordem Mundial e os governos nacionais se confrontam com as conseqüências da intensificação da mobilidade internacional de pessoas, capitais, empresas, conhecimento e informação. A velha ordem dos Estados-nação, as políticas de soberania nacional, não são mais as mesmas na medida que a mobilidade internacional se tornou uma nova força histórica, esvaziando-as também de poder.

Para fazer face à nova dinâmica de relações território-política, os Estados se associam para promover processos de integração regional em todo o mundo, do ASEAM, ao NAFTA, ao MERCOSUL, à CEE. Quando não é possível realizar modelos ambiciosos de integração, os Estados vêm se limitando a reduzir barrei- 
ras alfandegárias. Trata-se, de qualquer forma, de decisões estatais que limitam voluntariamente a soberania nacional e alargam o campo de poderes supra-nacionais (Di Giorgi, 1993).

Pari passu, ao lado desse esforço de integração, conota-se a Nova Ordem Mundial com a idéia de fragmentação, advinda dos fatos que se verificaram com a dissolução da URSS, a criação de novos Estados na Europa Oriental, o desmembramento da Iugoslávia nos Bálcãs e outros menos explorados pela mídia, associada a movimentos mais, ou menos, ordenados de fluxos populacionais de variada origem.

Tais movimentos, aliados à criação de processos políticos de promoção de integração regional, têm como substrato a intensificação planetária dos fluxos migratórios, determinando a proximidade territorial de grupos portadores de heranças de vários passados civilizatórios, reproduzindo, no patrimônio assim gerado, características sociais e políticas de relações étnicas e culturais que historicamente o engendraram. Nesta situação, emergem duas novas formas de internacionalismo, representadas por dois extremos de uma dimensão utópica. Ser de todos os lugares e tempos, ao mesmo tempo, convivendo em ordem em um mesmo espaço, em uma patente mistura de origens e nacionalidades - a aceitação da diversidade grupal - é um desses pólos. Em contraposição, molda-se, também, uma visão naturalística e racista, que desloca os valores constituintes da nação, como o da vontade e o da consciência, remontando-os a um a priori fixo e imutável, de caráter forçosamente étnico. Este caráter implica a hostilidade a cada miscigenação com sangue estrangeiro - a negação da diversidade, do outro.

A esse respeito e ainda sob tais considerações, não se pode ignorar, como já exposto, que o quadro mundial contemporâneo vem se caracterizando, de um lado, pela disseminação de informações chamada pós-moderna e pela pretensa descentralização democratizadora; de outro, pelo crescimento das formas mais concentradas de acumulação de poder e centralização transnacional da cultura que a humanidade conheceu. Nesse processo, diferenças regionais ou setoriais, originadas da heterogeneidade de experiências culturais, e a divisão técnica e social do trabalho, são elementos estratégicos, pois, podem ser (e vêm sendo) utilizados por categorias sociais hegemônicas na obtenção de uma apropriação privilegiada do patrimônio comum (Canclini, 1989). Assim, embora os patrimônios culturais sirvam para unificar nações e agregados nacionais, o enfoque geopolítico na sua análise exige que se os estude como espaço de luta material e simbólica interclasses, grupos e etnias, face às ditas desigualdades em sua formação e apropriação (Bourdieu, 1970). Tal princípio metodológico corresponde ao caráter complexo das sociedades contemporâneas, industriais e capitalistas, em função da realidade econômica hodierna que domina o sistema-mundo.

Sob tal ótica e do ponto de vista sociológico, pode-se, portanto, afirmar que, a este propósito, o conhecimento histórico traz analogias que permitem conclusões. Em primeiro lugar, pode-se inferir que as relações planetárias contemporâneas entre fluxos migratórios são manifestações cíclicas da re-organização 
da produção mundial. Em segundo, que tal re-organização se faz sob o aprimoramento de condições científico-tecnológicas a ela inerentes, implicando o incremento da eficiência de subordinação de humanidades ao processo produtivo capitalista. Esse aprimoramento se processa pela diminuição do conhecimento compreensivo sobre o trabalho e do poder sobre o processo científico, por sua vez também subordinado ao processo produtivo, agora sob regime mercantil. Ou seja, fluxos migratórios expressariam processos de substituição de determinados grupos sociais arruinados no processo produtivo por novos outros, e sua intensificação significaria o aumento da força de reprodução de papéis sociais estruturalmente fracos. Assim, constituem violentos processos de revolução social e de criação de conflitos gerados pelo empobrecimento e pela miscigenação forçada advindos da expulsão de grupos sociais do processo mundializado de produção.

Portanto, se por um lado constata-se que a economia-mundo capitalista foi hábil para se expandir de sua base européia inicial até incorporar o mundo inteiro e eliminar todos os outros sistemas históricos do globo (Wallerstein, 1993), por outro, vivencia-se o momento contemporâneo como uma época de desintegração do sistema histórico vigente.

Assim configurada, a Nova Ordem Mundial apresenta-se também como uma expectativa de algo ainda a ser criado, expectativa esta que, com base na vivência dos indivíduos como homens planetários, pode ser interpretada como um mero grito em vão "no qual quase ninguém acredita e, em todo caso, de realização pouco provável” (Wallerstein, 1994:150).

As forças do nada, a propaganda e a história: proposta para um novo humanismo

\footnotetext{
"Não me propus formular uma nova teorização da realidade no final do século. Procurei, pelo contrário, desteorizá-la para poder depois utopizar com o objetivo de contribuir para a criação de um novo senso comum que nos permita transformar a ordem ou desordem existente que Fourier significativamente designava por 'ordem subversiva'.

Não é tarefa fácil nem é uma tarefa individual. Mas se é verdade que a paciência dos conceitos é grande, a paciência da utopia é infinita."
}

Boaventura de Sousa Santos (1995:346)

O descrédito na possibilidade de construção de uma verdadeira Nova Ordem Mundial, misto de onipotência e impotência frente à participação dos indivíduos na construção do futuro, é resultado da apontada ação de forças sociais sistemáticas em luta pelo controle político pelo processo histórico. Sob tal perspectiva, as ausências que permanecem no horizonte do mundo contemporâneo são produzidas mediante um despótico comando estratégico, que expressa uma elaboração instrumental de um grupo de interesses em uma situação de conflito frente ao processo histórico, tendo em vista impor e manter uma dada represen- 
tação da história, como compartilhada pelas diversas humanidades da Terra. Em outras palavras, as ausências são resultado de uma ação de propaganda (Moscovici, 1961), produzindo, pela organização e propagação de princípios e temas sistemáticos, uma visão de absoluta pré-determinação do futuro histórico. Uma representação da história produzida pelo deslocamento da ideologia liberal para sua transformação frente à desintegração do sistema histórico - a ideologia da vitória dos grupos mais aptos impondo-se aos demais, vistos como naturalmente recessivos e em extinção. Apresenta-se, assim, legitimada a exclusão de grupos, $o$ confinamento de excluídos em territórios de não-integrados, cujos desejos, criados e interditados pelo sistema, constituem-se ao mesmo tempo em propulsores das possibilidades e modalidades de inclusão virtual no mesmo (Kurz, 1993).

Encontramo-nos, desta forma, diante de um dilema - o indivíduo, o herói do liberalismo, carece de um papel significativo frente às estruturas em desintegração, determinando sua morte como sujeito histórico, dado que nenhum indivíduo pode sobreviver por muito tempo em tais estruturas, atuando por si mesmo. Nasce dessa decomposição, o grupo como um novo sujeito histórico. Mas, afirmar o grupo como sujeito não é suficiente. Torna-se necessária a apresentação de um programa político, de uma ideologia, baseada na primazia dos grupos como atores. Como, neste contexto de luta assimétrica entre forças sistemáticas e anti-sistemáticas, podem se aglutinar prospectos de desintegração com prospectos de mudança normal progressiva?

Wallerstein (1994) propõe uma ideologia alternativa à da sobrevivência dos mais aptos e que pode se erigir em torno da primazia do grupo em uma época de desintegração. É a ideologia que reconhece os direitos de todos os grupos de participar na reconstrução do sistema mundial e, ao mesmo tempo, reconhece a não-exclusividade dos grupos. Porém, do ponto de vista racional, a criação de um verdadeiro espaço para os grupos no sistema social implica necessariamente a criação de espaço dentro dos grupos. Todos os grupos representam identidades parciais. As fronteiras defensivas desses grupos tendem a trazer, como conseqüência, o estabelecimento de hierarquias dentro dos mesmos e, naturalmente, sem algumas formas de defesa os grupos não podem existir. Concluindo, Wallerstein (1994:153) afirma que “... as forças anti-sistemáticas deveriam concentrar-se na expansão dos grupos sociais, em um movimento unificado ... a batalha para transformação somente pode se dar em todas as frentes ao mesmo tempo ... pressionar em todas as frentes para uma maior democratização na tomada de decisões, para eliminação de todos os recursos de privilégios, mesmo os informais, não-reconhecidos e velados...”.

As estratégias que convergiriam para a produção dessa qualidade de resultados, certamente devem ser novas estratégias, não-contaminadas pela ideologia liberal dominante da economia-mundo capitalista. Estruturá-las, no entanto, exige a análise das condições que sustentam e reverberam, em nível das relações humanas, esta apontada hegemonia que mantém a submissão e retira a autonomia.

Produzir tais resultados implica necessariamente a proposição de uma dou- 
trina humanista, que possa vir a sustentar a construção de relações humanas compatíveis com a preconizada ideologia de valorização da diversidade dos grupos, instaurando uma cultura da paz e formando um modelo planetário de homem (Balducci, 1990).

Tal proposição requer, como ponto de partida, o desenvolvimento de uma crítica de cunho antropológico do fundamento da hegemonia européia no mundo, considerando como fato que influenciou prevalentemente a constituição da consciência moderna, "a recusa, o extermínio, a negação do outro" (Balducci, 1991:165). "A época moderna começa com a negação do outro e desde então o Ocidente nunca mais encontrou o outro. Aonde foi, o homem europeu encontrou a si mesmo, não saiu de seu panorama e toda vez que encontrou a diversidade, a exterminou e a reprimiu" (Balducci, 1991:43).

Falando a respeito da conquista do Novo Mundo, Balducci a analisa e avalia como paradigma da modernidade: no sentido político e geopolítico, porque consiste na unificação eurocêntrica do mundo e instauração de um sistema fundamentado na acumulação econômica primitiva violenta e sobre o seqüestro sistemático de bens; no sentido cultural, porque afirma a superioridade e unicidade da cultura européia, e o conseqüente direito-dever de impô-la; no sentido educativo, porque implica a formação de dois modelos de homem e de povo, destinado o primeiro a dominar e o segundo a submeter-se (Girardi, 1993).

Dessa forma, pode-se concluir que a ideologia ocidental é parte integrante de tal sistema de domínio, fornecendo-lhe justificativa e exaltação, representando paradigmaticamente a modernidade histórica. A fé velada no progresso ilimitado, o persistente etnocentrismo e o inquebrantável militarismo são fundamentos ideológicos para o exercício da função hegemônica do Ocidente.

Assim, a opção planetária de homem preconizada terá que necessariamente se contrapor à ética da competição, substrato das violentas formas de internacionalismo forçado vigentes no sistema-mundo. A interdependência entre os homens neste sistema, contudo, remete ao seu panorama contexto que é o sistema de interdependência entre o Norte e o Sul. "A consciência verdadeiramente humana coloca-se no ponto de resolução da dialética entre os dois hemisférios, uma resolução que não poderá ocorrer só no plano cultural, deverá em primeiro lugar colocar em questão a ordem econômica internacional" (Girardi, 1993:19).

Tal colocação introduz uma outra dimensão de exigência tendo em vista a superação de obstáculos impedidores da construção de um homem planetário e de uma ética da interdependência, fundamentando relações humanas compatíveis com uma cultura de paz, substrato do respeito à diversidade dos grupos - a crítica da racionalidade ocidental visando-se à recuperação da dialética do iluminismo, delineada por Horkheimer e Adorno, logo após a Segunda Grande Guerra.

Para desenvolver a reflexão coletiva sobre as autênticas necessidades sociais, 
subtraindo-as dos imperativos das falsas necessidades e do consumismo, Habermas (1987) propõe a organização social de zonas sempre mais extensas de racionalidade discursiva, com acesso ilimitado de participantes e ausência de coação. Elas contrapor-se-iam à racionalidade tecnológica, ideologicamente instrumentalizada pelo domínio.

Tal faculdade reflexiva, ou competência comunicativa, permitiria a individuação e a colocação em luz das distorções, assimetrias e censuras que condicionam, no plano histórico-crítico, qualquer processo factual de comunicação. A reflexão crítica dos papéis sociais significa para Habermas, neste sentido, discorrer sobre as condições do discurso, tematizando os vínculos de poder e dissolvendo a aparente naturalidade da falsa consciência ideológica e psicológica. Viria, assim, desencadeado um processo irresistípel de auto-esclarecimento da consciência, em grau de tematizar publicamente aquilo que a instrumentalização autoritária do preconceito teria interesse em manter oculto. $\mathrm{O}$ pensamento de Habermas, dessa forma, contrapõe a eficácia política da reflexão comunicativa à racionalização aparente do sistema tardo-capitalista.

Sob tais inspirações, resta ainda a grande questão: como colocar em movimento forças anti-sistemáticas que possam vir a se aglutinar na direção desta produção histórica de um homem planetário assim conceituado?

A verificação, no plano empírico-sociológico, de quaisquer desses paradigmas transformadores apoia-se em um a priori - a competência de leitura do panorama vigente de relações homens-grupos-sociedades-humanidades e, como tal, para desenvolvê-la, exige o domínio de códigos transicionais situados no campo teórico da psicologia social.

\section{A análise crítica do status quo à luz da psicologia social}

\footnotetext{
"Na terceira revolução industrial, a capacidade de racionalização é maior do que a capacidade de expansão. A eficácia de uma fase expansiva, criadora de empregos, deixou de existir. O desemprego tecnológico da antiga história da industrialização faz seu retorno triunfal, só que agora não se limita a um ramo da produção, mas se espalha por todas as indústrias, por todo o planeta."
}

Robert Kurz (1996: 5-14)

Se o social, como se pode compreender a partir da leitura de Freud, é o terreno da ilusão, da busca de certezas, de segurança, de reconhecimento pelo outro, ele é também o terreno do poder, do jogo, da manipulação. Por ser o humano duplamente caracterizado pelo pulsional e pelo social (Enriquez, 1983), é o jogo de pulsões que fundamenta e estrutura o psíquico e o social, movimento para fora, em busca do outro que deve reconhecer nossa existência, nossas necessidades e nossos desejos e gratificá-los ou não. 
É na relação mãe-bebê que o vínculo de poder se inicia, dada a absoluta dependência que nós, seres humanos, temos com relação aos primeiros objetos (mãe ou substituta) que nos assistem, sem os quais não sobreviveríamos. Apesar de nossa pretensa onipotência, estamos completamente à mercê das condições impostas pelo meio que nos circunda. E mais: sujeitos a identificar-nos com nosso agressor quando oprimidos por um objeto agressivo (como mostra Anna Freud), em uma tentativa desesperada de apaziguarmos o objeto, buscando evitar ou reduzir o mal estar criado com a opressão. A imitação física ou moral da pessoa do agressor, ou ainda, a adoção de seus símbolos de poder confirmam a necessidade de eliminar a diferença que denuncia a ameaça. Inconscientemente, tentamos ficar iguais ao agressor para não sucumbirmos diante dele.

O homem traz, então, como modelo em sua vida mental um vínculo de poder e vai repeti-lo na vida social, procurando estabelecer uma relação dominador-dominado, já inscrita em seu inconsciente. Ao voltar-se para o externo, para o mundo social em busca de satisfação de suas necessidades e desejos, 0 homem já possibilita ao outro o estabelecimento desse vínculo, construindo relações de amor e ódio, de gratificações e frustrações, de troca ou jogo e manipulação, através das quais sua identidade se constitui.

As estruturas sociais são, assim, habitadas pelo sujeito psíquico, que traduz as singularidades, as especificidades de cada um, o sujeito vivido, histórico. Tais estruturas tornam-se palco dessas relações de vida e morte através dos sujeitos que as habitam e lhes dão significação, imprimindo nelas suas fantasias e desejos.

Em decorrência das especificidades do ser humano, da necessidade de se considerar suas características particulares, de respeitar as singularidades que o definem como tal quando se pensa em vida social democrática, é preciso pensar na impossibilidade da igualdade, como é vulgar e falsamente concebida. A igualdade democrática (que na prática se traduz pela padronização dos indivíduos, pela homogeneização dos desejos), levada às últimas conseqüências, conduziria à eliminação do singular, do diferente, do distintivamente humano, da alteridade e da verdadeira liberdade, que é a autonomia de cada um na produção de suas necessidades e desejos.

Entretanto, uma questão fundamental se coloca: como conciliar o respeito à singularidade, à diferença, à necessária autonomia do sujeito, em um contexto de globalização, com todas as implicações daí decorrente? Como conciliar etnocentrismo com multiculturalismo? Heterogênese da história com a hegemonia das metas que visam à unificação de aspirações, desejos, necessidades que garantam um mercado comum e, portanto, a dominação completa com a uniformização do discurso?

Marcuse (1966) já nos mostra que a operacionalização da dominação efetuada pela tecnologia através do fechamento do universo da locução, leva a comportamento unidimensional, tecnológico, produzindo hábitos de pensar sociais, ao uniformizar o que é diferente. Analisando-se a questão dentro da temática da 
mundialização, temos o mercado redefinido pela grande indústria, organizado em níveis estatal, internacional e transnacional, fazendo com que os indivíduos se relacionem no limite das disponibilidades de troca. A igualdade é mistificada e, da mundialização, chega-se à dominação, com a criação de regras universais para pensar, necessitar, desejar, consumir, viver.

O fechamento do universo da locução como condição para padronizar o humano é assentado no discurso da racionalização, típico da sociedade contemporânea, forma de perversão da razão, distante do discurso racional. Assim, o controle ideológico, mediado pela tecno-eletrônica, garante a eficácia do discurso e mantém o vínculo de poder, a relação dominador-dominado. Refletir o desejo do povo é uma proposição que se inverte e toma o sentido oposto: indicar ao povo quais são os seu desejos. Além do princípio do prazer, está a pulsão de morte. Além do cidadão Kane, está a tele-tela do Grande Irmão, a aprisionar a consciência no presente imediato, rompendo seus vínculos com o passado, impedindo-a de reconhecer o trabalho da repressão e da apropriação de sua autonomia, de sua vida, de seu futuro.

Fromm (1972), ao discutir a relação entre consciência e sociedade industrial, afirma que grande parte do que acreditamos ser verdade é apenas o consenso da maioria, manipulado pelos que detêm o poder. Assim, o consenso da maioria (com o viés da manipulação) é subjetivamente experimentado como real, verdadeiro, racional e moral. A partir daí podemos levantar uma importante questão: como a democracia pode ser o governo da maioria, aquilo que a maioria quer, quando, por detrás dessa maioria existem os grupos de interesses, as minorias-elite, que impõem e manipulam esse querer, a verdade, a realidade $\mathrm{e}$ tudo o mais que a tele-tela tão competentemente trata de propagar?

Fromm nos oferece mais elementos para reflexão ao afirmar que cada sociedade cria uma espécie particular de pensamento, ou seja, uma espécie particular de inconsciente social, necessário para a sua sobrevivência e funcionamento. Esse sistema de conhecimento funciona por meio de um esquema pré-fabricado que determina qual parte do conteúdo se fará consciente e qual permanecerá inconsciente. Fromm denomina de filtro social o mecanismo pelo qual esse processo se realiza. Um dos elementos desse filtro, segundo ele, é a massa de ficção manufaturada que qualquer sociedade transmite ao indivíduo. Aqui podemos identificar o processo de lavagem cerebral que a mídia e certas formas de educação promovem.

Pode-se pensar, então, o quanto é difícil se afirmar a identidade, se manter a autonomia e participar criticamente da realidade dentro das condições que a sociedade atual impõe. Não é por acaso que o discurso da mundialização, típico da sociedade ocidental e da lógica de produção capitalista, no qual aparece como dado fundamental a submissão da investigação científica ao processo produtivo, tem sua expressão máxima no meio urbano. A reprodução do modo de vida urbano é parte fundamental da estratégia de domínio que constrói a hegemonia típica dos detentores do mercado no mundo massificado. Há uma uniformização dos pensamentos que não permite a aceitação da contradição que leva à 
dialética, à percepção da existência de diferentes como necessária à própria construção da subjetividade. Assentado em uma falácia democrático-igualitária, tal discurso esconde o fundamental: as necessidades e desejos que imprimem dinâmica à vida psíquica e social não são os mesmos para todos porque a diferença faz parte da especificidade do humano. É preciso não esquecer o que é comum e o que é singular. Assim como é preciso lembrar que a igualdade democrática não significa que todos tenham igualmente a possibilidade de participar do processo produtivo (Damergian, 1992).

Assim, o que temos no campo da dominação ocidental é a intensificação da racionalidade comunicacional como estratégia de hegemonia, assentada no binômio propaganda/dominação. Ao impor representações sociais como se fossem naturais, a propaganda contribui enormemente para a alienação do sujeito com relação às alternativas existentes, uma vez que seu objetivo é esconder a luta concorrencial. Cabem, aqui, as considerações de Fromm a respeito dos filtros sociais e de seu papel na criação da realidade e da consciência social e, conseqüentemente, da inconsciência e alienação. Temos que considerar, ainda, o peso da comunicação de massa modificando nossa concepção de tempo e realidade. Não é possível se deixar de lado o significado ficcionado e alienante da realidade editada, a alterar ainda mais a nossa consciência, o nosso conhecimento e a nossa compreensão da realidade, reduzindo ainda mais nossa possibilidade de nela intervir criticamente.

Torna-se cada vez mais evidente a utilização das tecnologias da comunicação como estratégia de dominação e eliminação fictícia das fronteiras, uma vez que o mundo passa a ser apresentado como se fosse uma pequena aldeia global, como já afirmou McLuhan, na qual todos são cidadãos sempre bem-vindos, bem acolhidos e da qual podem participar em igualdade de condições. Por detrás dessa ficção, a realidade é bem outra: as diferenças permanecem, as minorias persistem como objeto de preconceito e discriminação. Mais além da pretensa aldeia global que acolhe indistintamente os cidadãos do mundo, está a ação dos grandes blocos econômicos, a criar formas de impedir a nova invasão de hordas de bárbaros: os migrantes e imigrantes que se locomovem em todas as partes do mundo em busca de melhores condições de vida ou de pura sobrevivência.

A aldeia é global, o mundo é de todos na hora de se dividir o prejuízo dos grandes interesses oligopólicos, provocados pela política econômica em vigor no contexto da mundialização. Por outro lado, a aldeia é bem particular quando se trata de impedir os invasores de participar dos paraísos econômicos. Assim, a questão das fronteiras que a mídia eletrônica tão bem manipula, coloca-se de modo ilusório: vale como impedimento para as minorias étnicas e culturais e não vale na hora de se dividir os prejuízos causados pelo jogo econômico-financeiro.

É preciso pensar o que está por detrás desse jogo de manipulação e poder que interdita o deslocamento dos diferentes, os confina em guetos, impedindo que grandes parcelas da população mundial tenham acesso à satisfação de suas necessidades mais elementares. Estamos diante de uma crise do humano, ameaça- 
do em sua sobrevivência devido à impossibilidade da troca da experiência e dos investimentos afetivos indispensáveis à constituição da subjetividade e da alteridade.

A verdadeira democracia, então, opõe-se à mundialização e às leis de mercado, a menos que haja a aceitação do diferente, a superação do que Freud chamou de "narcisismo das pequenas diferenças": fenômeno de ódio ou desprezo contra o exterior que reforça a coesão do grupo e o coloca em posição de guerra potencial contra os inimigos - os de fora, os estranhos. E o meio urbano se apresenta como cenário ideal para essa guerra de guerrilhas, uma vez que ele se transforma em locus de convergência das grandes correntes de interesses econômicos, políticos e ideológicos, cujo modo de vida a mídia trata de reproduzir como forma de garantir a hegemonia.

Dentro do quadro recessivo mundial e, particularmente, dentro do quadro brasileiro, o que se produz é uma concentração cada vez maior de grandes segmentos da população em pequenas áreas, postos na periferia do sistema, uma vez que pouco conseguem usufruir dos benefícios que o mesmo alardeia a muitos. À sua volta, estão aqueles que se vêem ameaçados de vir a estar fora do sistema, de perderem seus empregos, seus status. As tensões existentes dentro de seus próprios grupos são postas fora, nos estranhos, diferentes, vistos como causadores de seus males. E o diferente transforma-se em inimigo. Assim, o inimigo é o pobre que vive nas favelas ou nas ruas; é o migrante seduzido pela vida das grandes cidades; é o negro; são os meninos de rua, os que estão fora do sistema.

Ao mesmo tempo em que as exigências da mundialização apelam para a eliminação das fronteiras, que já vimos ser ilusória, colocando-nos diante de uma realidade de complexidade cultural extrema, o fenômeno do etnocentrismo se intensifica na Europa e em outras partes do mundo. Ele se expressa através de uma xenofobia violenta, a ponto de perseguir o estrangeiro até a morte, com o recrudescimento, inclusive, de movimentos neonazistas. À guerra fria sucedeuse a guerra econômica, com a criação de grandes blocos hegemônicos. A automação e a cibernética produziram o desemprego estrutural. E tudo serve de justificativa para a busca de responsáveis por todas as ameaças: os estranhos, estrangeiros, os out-groups - alvo da discriminação e da violência.

Não estamos imunes, no Brasil, à discriminação étnica, racial, social, econômica. Muito menos aos bárbaros homicídios praticados contra menores de rua. Contudo, as características peculiares da formação do povo brasileiro, a miscigenação e o choque cultural que levaram Darcy Ribeiro (1995) a definir o Brasil como uma Roma tardia, lavada no sangue negro e índio, nos possibilitou a vivência de um quadro de complexidade e riqueza cultural muito específicas. A nossa participação nesse processo de hibridismo cultural, nessa Roma tardia, marcada por profundas diferenças regionais, culturais, econômicas e sociais, como conseqüência do sofrimento que tem causado, permite-nos, por outro lado, nova visão da mundialização.

A experiência dessa vivência possibilita-nos o oferecimento de uma outra 
leitura da mundialização, de como é possível o estabelecimento de diálogos interculturais, problema novo para a Europa mas antigo para nós, na tentativa de alcançar um novo iluminismo, como proposto por Habermas, através da abertura do universo da locução. O mundo massificado é ausente de diálogos. Impõe um discurso padronizado na tentativa de eliminar as diferenças como forma de eliminar os limites que estruturam as identidades. É evidente que isso só vale para situações que atendam aos interesses do status quo, como já exposto. Para a realidade efetiva, as fronteiras continuam bem demarcadas, o diferente ameaça e não entra, a igualdade não existe.

É preciso, então, pensar as conseqüências da ausência de diálogo, da uniformização do discurso e sua propagação através da mídia na tentativa de padronizar, sabotando os limites definidores das identidades. Assim como a troca de experiência é fundamental para a construção da subjetividade, a aceitação do outro como singular, como ser desejante, inscrito em um sistema simbólico, portador de uma identidade psíquica e de uma identidade cultural, é crucial para a sobrevivência do humano. Quando o contato intercultural leva a um choque em que o dominador tenta eliminar as diferenças que caracterizam o dominado (o que já ocorre, inconscientemente, por parte do dominado, através da identificação com o agressor), não é apenas a sobrevivência de uma dada comunidade cultural que está ameaçada. O humano está ameaçado.

Por detrás da ilusão de que as mídias levam o homem e a informação a todas as partes do mundo ao mesmo tempo, tornando o homem um ser multidimensional, a realidade é bem diferente. A impossibilidade de decodificar o mosaico de mensagens destituídas de seu conteúdo simbólico, a concretude que elas carregam, ao mesmo tempo em que impedem qualquer reflexão, nos impõe uma opinião padronizada como se fosse uma verdade absoluta. Ao invés de multidimensional, o homem contemporâneo nada mais é que o ser unidimensional de que fala Marcuse: sem opinião, sem desejos próprios, sujeito/ objeto da manipulação social, fechado em seus círculos etnocêntricos, em busca de bodes expiatórios - os estrangeiros, os diferentes - para responsabilizá-los por suas mazelas.

Como se vê, a negação do outro leva à própria negação. Por outro lado, a possibilidade do estabelecimento de diálogos interculturais, com toda a sua vivência de complexidade e riqueza, está intimamente ligada ao resgate da história em oposição à história de seu fim, da recuperação das diferenças semânticas que fundamentam o discurso do outro, por meio da troca que constitui o sujeito e seu alter. É preciso que a experiência brasileira, derivada de um passado de mais de quatro séculos de multiculturalismo, não tenha sido um sofrimento em vão por parte daqueles que tiveram de absorver a cultura que se expandia, identificando-se com o agressor, obrigados a aprender a falar a sua língua com sangue e dor para serem considerados latinos. Ao contrário, que ela contribua para promover a abertura do universo humano, para a imperiosa necessidade de construção de uma utopia pacifista e humanista que seja capaz de transcender à anunciada morte do sujeito. 


\section{A ética na psicologia social à luz da psicanálise: para um novo humanismo}

"A derrota política dos pobres é tão acachapante nas sociedades pós-industriais que eles próprios acabam se convencendo de que são um peso para a comunidade e não merecem mesmo que os mais favorecidos se sacrifiquem por eles ... Evidências como essas me levam a acreditar que uma guerra de palavras contra os pobres está conseguindo, pela primeira vez neste século, matar o espírito e rebaixar o moral dos perdedores da guerra econômica ... Tem de haver comprometimento a longo prazo para quebrar o ciclo que perpetua a pobreza e seus problemas. Pobre tem professor pobre, advogado pobre, médico pobre. Eu insisto em que é preciso quebrar o ciclo da pobreza não apenas remediá-lo eternamente."

Herbert Gans (1996:8-10)

É preciso nos perguntarmos sobre as relações que podem ser estabelecidas entre a psicologia social, o entendimento da história e a ideologia que fundamenta um novo humanismo. Um caminho pode ser trilhado sob inspiração da concepção oferecida por Enriquez (1983:52), segundo a qual “a psicologia social é o estudo das formas de alteridade e, como tal, deve criar seu lugar e um lugar essencial aos investimentos afetivos, sem os quais grupo organizado algum chegará a se constituir”.

Pensar nas formas de alteridade implica pensar nos modos pelos quais se estabelecem as trocas entre os seres humanos, fundamentais para a construção da subjetividade, uma vez que o sujeito se constitui pela existência do outro. Implica, também, pensar na diferença. O alter, o outro, que nos ama, fala, olha, odeia ou nega é diferente de nós e é fundamentalmente necessário que nos aceitemos em nossa mútua diferença, o que nos faz singulares. A identidade, marca específica do sujeito humano, não apenas se constrói nesse processo mas também se mantém, ou não, através dele.

Entretanto, ao observarmos as condições sob as quais vêm se estabelecendo as trocas entre os seres humanos, não podemos ficar otimistas. Em primeiro lugar, o próprio conceito de troca fica comprometido diante da falta de reciprocidade, de solidariedade, de empatia, de capacidade para aceitar e acolher o outro. Graças às condições econômicas e sociais advindas do modelo político-econômico vigente, da globalização da economia, da Terceira Revolução Industrial, que promovem o aumento da recessão, dos privilégios e do desemprego, as relações humanas estão degradadas.

A competição pelas ofertas cada vez menores de emprego e a conseqüente ameaça de desemprego e de perda daquilo que garante as condições básicas para a sobrevivência, o apelo ao consumo que não pode ser concretizado e, o pior, os contingentes de excluídos e o decorrente aumento da violência e do ódio social, tornam a convivência entre as pessoas cada vez mais problemática. 
Falar em alteridade, construção da subjetividade, identidade psíquica e identidade cultural parece, às vezes, um exercício de ficção quando nos deparamos com as condições da vida contemporânea. Sabemos da importância da existência de um espaço interno, psíquico, no qual o sujeito possa viver suas emoções - como Heller acentua - para a preservação da identidade do sujeito. Entretanto, quando constatamos o aumento ininterrupto de pessoas que o sistema excluiu e transformou em moradores de rua, sem teto, sem privacidade, sem sequer um espaço que separe o público do privado, totalmente expostos e invadidos pelos olhares curiosos ou indiferentes dos passantes, fica difícil pensar em preservação da identidade, na sobrevivência do sujeito. Sem teto, sem emprego, sem perspectivas, sem o mínimo que garanta a dignidade humana, diante do olhar especular do outro.

Para não falar nos meninos de rua, alvo da intolerância e da violência de determinados segmentos da sociedade, rejeitados e exterminados com a conivência do poder público. Sem presente e sem futuro. Onde está o acolhimento, a função materna que a sociedade não exerce, diante do olhar complacente do outro?

É possível imaginar que tipo de trocas e que formas de alteridade se estabelecem nas sociedades mundializadas contemporâneas. E quando Enriquez, como já referido, concebe a psicologia social como o estudo das formas de alteridade que, como tal, deve criar um lugar essencial aos investimentos afetivos, condição sine qua non para a constituição dos grupos organizados, a situação se complica ainda mais. De quais investimentos afetivos se está falando quando as grandes massas de migrantes e imigrantes que se deslocam pelo mundo, arrancadas de sua terra-mãe graças às condições impostas pela mundialização da economia, transformam-se em alvo de exacerbadas reações de etnocentrismo e xenofobia, expressas, muitas vezes, sob o signo da morte? E o que dizer do cruel massacre a que as chamadas nações civilizadas assistem passivamente na Bósnia, intitulado de limpeza étnica?

Poderíamos enumerar dezenas de exemplos que retratam as condições sob as quais se estabelecem as interações entre as pessoas. Ao invés da empatia, da reciprocidade, da aceitação do alter, do outro, do diferente, o que se acentua é a hostilidade, a intolerância, a violência, a discriminação, fundamentalmente contra o diferente. Que é o excluído, o marginalizado do sistema, o pobre, o negro, o índio, o que carrega as marcas de sua identidade cultural. E que é impedido de se expressar como ser desejante, como portador de uma identidade psíquica, como humano, enfim.

O que temos, então, é que as trocas indispensáveis à subjetividade são marcadas pela rejeição, pelo ódio, pela indiferença. Os investimentos afetivos na sociedade contemporânea são, em grande parte, da mesma ordem, ou seja, falta amor, fundamento para a bondade e o caráter. As pessoas são coisificadas e as coisas personalizadas. 
Carecemos, absolutamente, de uma consciência humanista, como diz Money-Kyrle (1969), ao conceber o humanismo como um atributo da compreensão, elo causal entre a posse de uma certa espécie de consciência e a posse de uma certa espécie de sabedoria. Ele está falando de indivíduos capazes de sentir o que está dentro deles, capazes de autoconhecimento, espécie de sabedoria fundamentada mais no amor que no medo.

A importância das concepções de Money-Kyrle para nosso problema é ele mostrar que nosso conhecimento de humanidades, em geral, e de psicologia, em particular, ou seja, o conhecimento de nós próprios e de outras pessoas, pode modificar nossas preferências morais e políticas, através da substituição de falsas crenças por verdadeiras. E é desse tipo de conhecimento e dessa espécie de sabedoria, fundamentada no amor, na capacidade de sentir culpa depressiva (culpa pelo dano causado ao objeto, medo de perder o objeto bom, impedindo que se faça mal ao objeto, tanto interno quanto externo - o outro) que a humanidade necessita em um momento em que as pessoas se relacionam de modo tão desumano e destrutivo, em que a ética se faz tão raramente presente.

Necessitamos de uma revolução humanista que se contraponha ao status quo aqui descrito. Como mostra Money-Kyrle, se a compreensão interna leva ao humanismo, é preciso que haja também um Estado compatível com tais pessoas. Assim, a meta política do humanismo seria um Estado que aceitasse a responsabilidade pelo bem-estar sem descartar a independência, convergindo no sentido de uma finalidade democrática.

Money-Kyrle acredita (e nós também) que o predomínio do tipo humanista de consciência modificaria o comportamento político de qualquer grupo, nação, classe ou partido com relação a outros grupos, assim como os indivíduos têm seu próprio comportamento modificado.

É evidente que as condições propostas por Money-Kyrle coincidem com as condições necessárias para as trocas verdadeiramente humanas, marcadas por uma ética humanista que permitam a construção e a manutenção da subjetividade, a aceitação do alter, do outro, a preservação da identidade psíquica e cultural, a verdadeira democracia.

É evidente, também, que não coincidem com as condições aqui descritas enquanto típicas da sociedade mundializada contemporânea na qual o outro, quando existe, é visto apenas enquanto extensão narcísica de egos grandiosos, sem direito ao desejo e à vida. É neste sentido que precisamos ter como ponto de partida o entendimento das interações tais como elas se apresentam neste dado momento histórico, como as personalidades se expressam historicamente através da vida institucional e social mais ampla e quais os componentes meta-históricos (inconscientes) que norteiam tais relações, ideologicamente manipuladas. Esta é uma tarefa da psicologia social (o que não quer dizer que deva ser executada apenas por ela). Se bem desempenhada, pode nos oferecer os elementos necessários à transformação da realidade, alicerçada nas relações que devem ser 
estabelecidas entre a psicologia social, o entendimento da história e a ideologia que fundamenta um novo humanismo.

A mídia como outdoor da representação da história: voluntarismo ou servidão involuntária? Tragédia anunciada ou profecia auto-realizadora?

\begin{abstract}
"A máxima força de um grupo dominante não está no exercício da força, mas no consenso dos dominados à própria subordinação"
\end{abstract}

M. Godelier apud Rosaria Micela (1984:78)

Comprometido com uma visão trágica da Nova Ordem Mundial, Touraine (1996:5-7) aponta para os riscos do pensamento único (ou pensamento unidimensional segundo Marcuse), afirmando que "para os países, o importante nos dias de hoje é sair da transição liberal e não ingressar nela". Tal posição é antagônica à da retórica específica da propaganda neoliberal. Segundo esta última, o necessário, o imprescindível, é o compromisso com a assunção do paradigma liberal, condição sine qua non para a construção de uma identidade de nãoexcluído, seja no plano coletivo, seja no plano individual.

Discorrendo sobre a fragilidade das forças anti-sistemáticas tendentes à criação de um novo controle social da economia, Touraine (1996:5-7) afirma que há um estreito caminho entre o intervencionismo estatal, obstáculo à modernização, e o liberalismo arrogante que "nos reserva inúmeras catástrofes, das quais a crise mexicana ou a desintegração política da Colômbia nos fornecem apenas os primeiros e dramáticos exemplos no continente". Dessa forma, as apontadas catástrofes não mais se prenunciam como alguma coisa para o futuro, o que poderia vir a sustentar uma interpretação de comprometimento com uma teoria conspiratória da história. Ao contrário, apresentam-se como ocorrências passadas com claros desdobramentos sobre o presente, deixando de ser ameaças para se transformarem em evidências históricas.

No panorama de uma luta estratégica entre paradigmas opostos - paradigma da "democracia autoritária" e paradigma da "democracia eco-socialista", segundo Boaventura de Sousa Santos (1995) -, marcada pela assimetria das forças em conflito e contextualizada pela virulência da propaganda neoliberal, o problema que se coloca, então, é o de como atuar com autonomia no trânsito interparadigmas.

A nosso ver, a conquista dessa autonomia está vinculada à mobilização de forcas anti-sistemáticas coincidentes, do ponto de vista psicológico, com a pulsão de vida, com os impulsos amorosos voltados para a construção de um coletivo solidário e não voltados para a produção de uma convivência hostil e competitiva, baseada no princípio ideológico da seleção natural aplicada ao social. Dessa forma, do ponto de vista intelectual, a possibilidade de uma ação voluntária com- 
patível com a construção de uma Nova Ordem Mundial comprometida, no mínimo, com a coexistência dos paradigmas citados, permitindo uma convivência entre minorias e maiorias, depende da compreensão dos obstáculos racionais impeditivos da fluidez de trânsito interparadigmas.

Do ponto de vista do indivíduo, a concretização desta fluidez sob forma de autonomia de decisão, que em termos afetivos significa a conquista da autonomia do desejo, depende da possibilidade da ruptura individual com a representação de mundo editada pela mídia comprometida com a ideologia dominante. Evidentemente, a mídia não é o único veículo a propagar tal ideologia mas é o mais forte dados seu alcance, penetração e caráter subliminar. As demais instituições - escola, família, instâncias políticas de Estado - também cumprem esse papel de veículo da propaganda oficial atuando como caixas de ressonância nas quais, ao mesmo tempo em que produzem a informação para a mídia, são instrumentos de sua propagação. Ou seja, a concretização da fluidez de trânsito interparadigmas depende, através do exercício da consciência crítica, da possibilidade de desmistificação da "falsa consciência" (Fromm, 1972) que a mídia produz, enquanto outdoor da representação social da história.

Ora, a representação social é um processo psicossocial básico e, como tal, é condição necessária a toda interação do indivíduo, seja com o seu meio social, seja consigo mesmo. Ela se reveste, portanto, de um caráter de universalidade quanto ao seu aspecto formal e de uma especificidade - variabilidade cultural quanto ao seu conteúdo. Como um processo, é perpassada pelos sistemas de significação, em seus componentes afetivos e cognitivos (Damergian, 1992).

Dessa forma, a representação da história, na medida que como representação social é uma condição necessária a toda interação humana, ao ser construída e imposta através da ação da mídia hegemônica, e das demais instituições já citadas, como um processo dado, conduz a um estado de servidão involuntária, elemento estratégico para a escolha prevalente do paradigma dominante, gerando dificuldades em se sair ou se opor a ele. Ao mesmo tempo, tal representação conduz as interações humanas no sentido de que sejam cada vez mais desumanizadas, impedindo o estabelecimento de um humanismo fundamentado na ética, na sabedoria, no amor e na culpa depressiva. Esses elementos não fluem espontaneamente dos processos psicossociais mas, ao contrário, são resultado de todo um movimento de construção da subjetividade, de amadurecimento emocional, que tornam possível a empatia e a solidariedade absolutamente indispensáveis a toda convivência que se pretenda humana.

A utopia humanista, a utopia de construção de uma "democracia ecosocialista" depende da desmontagem do "consenso ideológico dos dominados" (Godelier apud Micela, 1984), tarefa hercúlea diante da assimetria das forças em luta. "O fator mais forte não é a violência dos dominantes, mas o consenso ideológico dos dominados. Para mandar e conservar no poder uma parte da sociedade - seja ela formada pelos homens em relação às mulheres, por um grupo, uma casta ou uma classe com relação às outras -, a repressão serve menos do 
que a adesão, a força física serve menos do que a conviç̧ão ideal que implica a adesão e a cooperação voluntária (...). Portanto, é necessário que dominantes e dominados partilhem as mesmas representações, a mesma ideologia, para que se possa produzir o fator mais forte do poder dos primeiros sobre os segundos, ou seja, o consenso fundado no reconhecimento da legitimidade de tal poder" (Godelier apud Micela, 1984 p. 79).

Se o consenso ideológico dos dominados não puder ser rompido, a tragédia anunciada será, em decorrência, a morte do humano enquanto profecia autorealizadora. Por outro lado, a sobrevivência da história, através da crítica de sua representação social hegemônica, torna possível a desmontagem desse consenso, apresentando-se como a condição essencial para a realização da utopia humanista.

Referências bibliográficas

ANDERSON, Perry. Historiador faz balanço do neoliberalismo. O Estado de S. Paulo, Cultura. São Paulo, ano 15, n. 768, p. Q1 e Q2, 20 maio 1995.

ATTINÁ, Fulvio. Il sistema internazionale verso la globalizzazione. Politica Internazionale, ano XXI, n. 2 (nova série), p. 5-18, abr./jun. 1993.

La politica internazionale contemporanea. Milão, Angeli, 1989.

BALDUCCI, Ernesto. Le tribù della Terra: orizzonte 2000. San Domenico di Fiesole, Edizione Cultura della Pace, 1991.

Pace, 1990

L'uomo planetario. San Domenico di Fiesole, Edizione Cultura della

BOURDIEU, Pierre. Le marché des biens simboliques. Paris, Centre de Sociologie Européenne, 1970.

CANCLINI, Nestor Garcia. Culturas hibridas. Estrategias para entrar y salir de la modernidad. México, Grijalbo, 1989.

DAMERGIAN, Sueli. Fluxos migratórios e meio ambiente urbano. Seminário apresentado ao Grupo de Estudos sobre Urbanização e Meio Ambiente. São Paulo, USP, nov. $1992,8 \mathrm{p}$.

O papel do inconsciente na interação humana: um estudo sobre o objeto da Psicologia Social. São Paulo, 1988. Tese (doutoramento), Instituto de Psicologia da USP.

DI GIORGI, Umberto. Processi di aggregazione e di frantumazione. Politica Internazionale, ano XXI, n. 2 (nova série), p. 3-4, abr./jun. 1993.

ENRIQUEZ, Eugène. Da horda ao Estado. Psicanálise do vínculo social. Rio de Janeiro, Zahar, 1983.

FREUD, Anna. O Ego e os mecanismos de defesa. Rio de Janeiro, Civilização Brasileira, 1982.

Estudos AvanÇAdOS 10 (28), 1996 
FREUD, Sigmund. Psicologia do grupo e análise do Ego, v. XVIII Edição Standard Brasileira das Obras Completas de S. Freud. Rio de Janeiro, Imago Editora, 1976.

FROMM, Erich. Conciencia y sociedad industrial. In: Fromm, Erich; Horowitz, Irving Ionis; Marcuse, Herbert; Gorz, André; Olea e Victor Flores. La sociedad industrial contemporanea. México, Siglo Veinteno Editores, 1972.

GANS, Herbert. Pobreza tem solução. Entrevista concedida a Eurípides Alcântara. São Paulo, Veja, p. 7-10. jan. 1996.

GIRARDI, Giulio. Ernesto Balducci, teologo europeo della liberazione? Testimonianze, ano XXXVI, maio-jun. 1993.

GODELIER, M. Antropologia e Marxismo. Roma, Editori Riuniti, 1977.

Il sesso come fondamento ultimo dell' ordine sociale e cosmico nei buraya della Nuova Guinea. In: Sessualità e politica. Milão, Feltrinelli, 1976, p. 337 372.

HABERMAS, Jürgen. The theory of communicative action. v. II: Lifeworld and system: a critique of a functionalist reason. Boston, Beacon Press, 1987.

HELLER, Agnes. A morte do sujeito. Conferência proferida no Instituto de Psicologia da USP. São Paulo, 13 maio 1992.

HOBSBAWN, Eric. Era dos extremos. O breve século XX. 1914-1991. São Paulo, Companhia das Letras, 1994.

HUGHES, Judith M. Madness and social representations: living with the mad in one french community. The journal of interdisciplinary History, v. XXIV, n. I, verão 1993, p. 142-143.

KURZ, Robert. O torpor do capitalismo. Chega ao fim o mito da expansão ilimitada do mercado. São Paulo, Folha de S. Paulo. Mais!, p. 5-14, 11 fev. 1996.

O colapso da modernização. São Paulo, Paz e Terra, 1993.

MARCUSE, Herbert. One-dimensional man. Studies in the ideology of advanced industrial society. Boston, Beacon Press, 1966.

MARRAMAO, Giacomo. Organização social e complexidade. Jornal Brasileiro de Psiquiatria, v. 39, Suplemento 2, p. 10S a 13S, out. 1990.

MICELA, Rosaria. Antropologia e Psicanálise. Uma introdução à produção simbólica, ao imaginário, à subjetividade. São Paulo, Brasiliense, 1984.

MONEY-KYRLE, R.E. Psicanálise e ética. In: Klein, Melanie Heimann, Paula. Temas de Psicanálise aplicada. Rio de Janeiro, Zahar, 1969.

MOSCOVICI, Serge. La psychanalyse. Son image et son public. Étude sur la représentation sociale de la psychanalyse. Paris, PUF, 1961.

PESTRE, Dominique. Les Physiciens dans les sociétés occidentales de l'après-guerre. 
Une mutation des pratiques techniques et des comportements sociaux et culturels. Revue d'Histoire Moderne et Contemporaine, v. 39, n. 1, p. 56-72, jan./mar. 1992.

RIBEIRO, Darcy. O povo brasileiro. A formação e o sentido do Brasil. São Paulo, Companhia das Letras, 1995.

SCHWEBER, Sam. The empirist temper regnant. Theoretical physics in the United States, 1920-1950. Historical Studies in the Physical and Biological Sciences, 17, p. 5598, 1985.

SEABRA, Odete de Lima; TASSARA, Eda T. de Oliveira \& VICENTINI, Yara. Avaliação sócio-ambiental do Programa de Despolnição do Rio Tietê. Projeto de pesquisa em cooperação científica Brasil-Itália, incluído no Programa Território e Políticas de Desenvolvimento Sustentável nas Regiões Brasileiras. São Paulo/Turim, USP/Universidade de Turim, jan. 1994, 9 p.

SOUSA SANTOS, Boaventura. Pela mão de Alice. O sociale o politico na pós-modernidade. São Paulo, Cortez, 1995.

TASSARA, Eda T. de Oliveira. O processo de avaliação em tecnologia. Reflexões sobre o conceito de antecipação tecnológica. Exposição apresentada ao Seminário Tecnologia e Humanismo: Antecipação Tecnológica na Aeronáutica. Núcleo de Apoio a Cultura e Extensão Universitária de Arte, Tecnologia e Comunicação da USP. São Paulo, 26 abr. 1995.

La partecipazione italiana allo sviluppo della fisica in Brasile. Riflessione sulla scienza nel sistema-mondo. Seminário apresentado ao Dipartimento di Fisica da Università di Pisa. Pisa, 25 fev. 1994, 40 p.

TOURAINE, Alain. Riscos do pensamento único. São Paulo, Folba de S. Paulo, Mais!, p. 5-7, 18 fev. 1996.

WALLERSTEIN, Immanuel. El derrumbe del liberalismo. Secuencia, n. 28, p. 137-154, jan./abr. 1994.

30, n. 1, 1993.

The world-system after the cold war. Journal of Peace Research, v.

Resumo - A partir de uma leitura panorâmica da Nova Ordem Mundial e de uma análise do status quo à luz de teorias em psicologia social, neste artigo é desenvolvida uma crítica da antevisão do futuro de impostação neoliberal, interpretando-a como resultado de propaganda das forças sistemáticas sobre as representações sociais que se constrõem da história. Inspirando-se nas preconizações de Marramao, Wallerstein, Balducci, Habermas, Enriquez e Money-Kyrle, argumenta-se, em contraposição, pela necessidade da criação de um homem planetário capaz de se relacionar com base em uma ética de interdependência dos grupos e não da competição. Para tal, propõe-se, como estratégia, a organização social de zonas cada vez mais extensas de abertura do universo da locução e de promoção de redes de diálogos interculturais, como forma de construção de um novo humanismo. 
ABSTRACT - Starting from a panoramic reading of the New World Order and from an analysis of the status quo in the light of theories of Social Psychology, in this article is developed a critical view of the antecipation of a neoliberal future, interpreting it as the result of propaganda by systematic forces over the social representations created from history. Inspired by the ideas of Marramao, Wallerstein, Balducci, Habermas, Enriquez and Money-Kyrle, it argues, differently, for the need to create a planetary man, one capable of establishing relationships based on an ethics of the interdependency of groups and not on competition. In order to achieve that, it proposes the strategy of expanding the social organization of zones of widening speech and the promotion of networks of inter-cultural dialog, as a form of construction of a new humanism.

Eda Terezinha de Oliveira Tassara é professora do Departamento de Psicologia Social e do Trabalho da USP e professora-visitante do Departamento de Fisica da Universidade de Pisa, estudiosa das relações entre conhecimento científico e vida social e membro da Diretoria do Núcleo de Apoio à Cultura e Extensão Arte-Tecnologia-Comunicação da USP.

Sueli Damergian é professora do Departamento de Psicologia Social e do Trabalho da USP, responsável pela área de Psicologia das Relações Humanas e estudiosa dos aspectos inconscientes da interação humana. 